\section{Oncology}

Received: December 3, 2017

Accepted after revision: January 25, 2018 Published online: April 4, 2018

\title{
Expression and Clinical Implication of Autophagy-Associated Protein p62 in Osteosarcoma
}

\author{
Hangzhan Ma ${ }^{a-c}$ Xiaoyang Li ${ }^{b}$ Jinglu Wang ${ }^{b}$ Francis J. Hornicek ${ }^{b}$ \\ Cassandra C. Garbutt $^{c} \quad$ Xu Chang $^{\mathrm{a}}$ Zhenfeng Duan $^{\mathrm{b}}$ \\ ${ }^{a}$ Department of Orthopaedics, Panyu Hospital of Chinese Medicine, Guangzhou, China; ${ }^{b}$ Department of

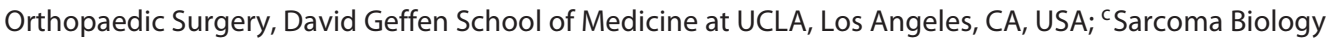 \\ Laboratory, Department of Orthopaedic Surgery, Massachusetts General Hospital and Harvard Medical School, \\ Boston, MA, USA
}

\section{Keywords}

p62 $\cdot$ Osteosarcoma $\cdot$ Autophagy-associated protein

\begin{abstract}
Purpose: Recent studies highlight the role of autophagy in cancer tumorigenesis, recurrence, metastasis, and chemoresistance. p62 is an adapter protein that is crucial for the autophagy pathway. In this study, we will describe the expression of p62 and its correlation with clinic prognosis in osteosarcoma. Methods: Western blot was used to test the expression of p62 in osteosarcoma cell lines (U2OS, KHOS, MG63, Saos-2, U2OSR2, KHOSR2, and 143B). A tissue microarray (TMA) was analyzed by immunohistochemistry to determine the expression levels of p62 in osteosarcoma patients and evaluate any correlation between p62 and clinical characteristics in osteosarcoma patients. Results: p62 was expressed differently in all cell lines. The TMA also showed differential expression in osteosarcoma tissues. Seventy-five of 79 (94.9\%) patient tissues exhibited p62 immunostaining, ranging from no staining (4 of $97,5.1 \%$ ) to $1+$ staining ( 40 of $79,50.6 \%), 2+$ staining (17 of $79,21.5 \%)$, and $3+$ staining (18 of $79,22.8 \%)$. The low staining (1+) was classified as the p62 weak group (50.6\%), the medium staining $(2+)$ and intense
\end{abstract}

staining (3+) were classified as the p62 strong group (44.3\%). Analyzing the clinical data of the osteosarcoma TMA, we found that the 5-year survival rate of patients with weak p62 expression was significantly lower than that of the patients with strong p62 expression ( $p=0.0165)$. Furthermore, the decreased p62 expression may be associated with higher metastatic and chemoresistant rates in osteosarcoma patients. Conclusion: Our results suggest that p 62 may be an effective predictor of prognosis and a potential target for therapy in osteosarcoma.

c 2018 S. Karger AG, Basel

\section{Introduction}

Osteosarcoma is the most common primary malignant bone tumor affecting both children and adolescents. It is responsible for $20 \%$ of all primary bone sarcomas [1]. The treatment strategy for osteosarcoma is preoperative chemotherapy, surgical resection of the tumor(s), and postoperative chemotherapy [2-4]. Although these treatments have improved the 5-year survival rate to $60-70 \%$, osteosarcoma retains a high mortality rate due to recurrence and metastasis, as patients who develop metastasis

\section{KARGER}

(c) 2018 S. Karger AG, Basel

E-Mail karger@karger.com

www.karger.com/ocl
Dr. Zhenfeng Duan

Department of Orthopaedic Surgery, David Geffen School of Medicine at UCLA 615 Charles E Young Dr. South, Biomedical Sciences Research Building, Room 410 Los Angeles, CA 90095 (USA)

E-Mail zduan@mednet.ucla.edu 
survive for less than 1 year on average [5-7]. Treatment and thus survival rates have not improved in almost 3 decades, which highlights the need for more effective therapeutic strategies [7].

Autophagy is a lysosome-mediated intracellular degradation and recycling pathway. Recent studies found that autophagy plays a role in tumorigenesis, recurrence, metastasis, and drug resistance in a variety of cancers, including osteosarcoma [8-10]. Autophagy contributes to the prolonged survival of tumor cells and begins with an autophagosome, a double-membrane vesicle that encloses cellular debris before fusing with a lysosome for degradation and recycling [11]. In addition, autophagy can selectively target and regulate cancer cell signaling proteins. Usually, the function and flux of autophagy are indirectly evaluated by related biomarkers, such as LC3, Beclin-1, and other autophagy-related proteins [9]. Latest studies have shown that autophagy-associated protein $\mathrm{p} 62$ plays a critical role in autophagy [12-14]. p62 is an autophagy substrate that accumulates and aggregates in autophagydeficient cells, and it also has key roles in tumor progression or metastasis. $\mathrm{p} 62$ is a cellular protein localized at the autophagosome formation site and directly interacts with LC3, another autophagosome-localizing protein, and it is incorporated subsequently into the autophagosome. Because of the interaction with proteins in different intracellular signaling pathways, p62 plays an important role at the crossroad of autophagy, apoptosis, and cancer [12, $15]$. Although expression of $\mathrm{p} 62$ has been reported in primary tumor tissues, there is little research on p62 expression in metastatic tumor tissues. The expression of p62 and the relationship between p62 expression and clinic prognosis in osteosarcoma are unknown.

This is the first study that examines the expression of p62 in osteosarcoma cell lines and tumor tissue samples. We also evaluate the association between p62 expression and clinical characteristics in osteosarcoma patients, especially those with metastasis and recurrence.

\section{Materials and Methods}

\section{Cell Lines and Cell Culture}

The human osteosarcoma cell lines U2OS, MG63, Saos-2, and 143B were obtained from the American Type Culture Collection (Rockville, MD, USA). The human osteosarcoma cell lines KHOS, KHOSR2, and U2OSR2 were provided by Dr. Efstathios Gonos (Institute of Biological Research and Biotechnology, Athens, Greece). Cell lines were maintained in RPMI 1640 supplemented with $1 \%$ penicillin/streptomycin and $10 \%$ fetal bovine serum in a $5 \% \mathrm{CO}_{2}, 37^{\circ} \mathrm{C}$ cell culture incubator.
Western Blotting Assay

Briefly, total protein was isolated with RIPA Lysis Buffer (Upstate Biotechnology, New York, NY, USA). The concentration of the protein was determined by protein assay reagents (SigmaAldrich, St. Louis, MO, USA) and a spectrophotometer (Beckman DU-640, Beckman Instruments, Inc., Indianapolis, IN, USA). Protein extracted from cell lysates was separated by SDS-PAGE electrophoresis and then transferred onto nitrocellulose membranes. Membranes were then blocked with 5\% nonfat milk in $1 \times$ TBST and then probed with a specific primary antibody for p62 (1:1,000 dilution, Cell Signaling Technology) and mouse monoclonal antibody for human $\beta$-actin (Sigma-Aldrich) at $4{ }^{\circ} \mathrm{C}$ overnight. Following primary antibody incubation, the membranes were washed with TBST (Cell Signaling Technology) and further probed with secondary antibodies IRDye ${ }^{\circledR} 800 \mathrm{CW}$ and IRDye ${ }^{\circledR}$ 680LT which were obtained from LI-COR Biosciences (Lincoln, NE, USA). After incubation at room temperature for $2 \mathrm{~h}$, the relative expression of protein was normalized using Odyssey Infrared Fluorescent Western Blots Imaging System from LI-COR Biosciences. Quantification of western blot results was analyzed with Odyssey software 3.0.

Osteosarcoma Tissue Microarray and Immunohistochemistry

A total of 79 osteosarcoma specimens were taken after informed consent was given from osteosarcoma patients who had surgery in the Orthopaedic Department of Massachusetts General Hospital from 1993 to 2010. Tissue microarrays (TMAs) of osteosarcoma tissues with paraffin-embedded (FFPE) blocks were provided by the Sarcoma Tissue Bank. To ensure that the selection included the core of the tumor, the 3 sites of each FFPE block were selected for assembling the recipient master block. TMA is produced by the Tissue Microarray and Imaging Core at the DanaFarber/Harvard Cancer Center. Hematoxylin and eosin-stained slides from each tissue block were read by a pathologist to obtain representative triplicate $0.5-\mathrm{mm}$-diameter core biopsies. All of the patients were treated by preoperative chemotherapy, and the clinical information was collected, including age, gender, tumor location, disease status (primary/metastasis/recurrence), and followup time. According to the patients' status, 79 specimens were divided into 3 groups (14 recurrence, 27 metastasis, and 38 primary). The samples were from 49 (62.0\%) males and 30 (38.0\%) females with a mean age of 31.4 years (range 10-74). All samples were followed up for a mean period of 82.2 months (range 1-273) after surgery.

The expression of p62 was dependent on immunohistochemical staining. First of all, $5-\mu \mathrm{m}$-thick array sections were baked at $60^{\circ} \mathrm{C}$ for $1 \mathrm{~h}$, dewaxed 3 times with xylene (each time for $5 \mathrm{~min}$ ), and then transferred by $100 \%$ ethanol twice (each time for $5 \mathrm{~min}$ ), rehydrated through graded alcohol, and lastly immersed in deionized water for $10 \mathrm{~min}$. Antigen retrieval was processed with Target Retrieval Solution (Dako North America, Inc., Carpinteria, CA, USA). After that, the slide was washed with PBS twice for 5 min. Following the process of antigen retrieval, endogenous peroxidase activity was quenched by incubation in $3 \%$ hydrogen peroxide. After the protein was blocked with blocking solution (Cell Signaling Technology) for $1 \mathrm{~h}$ at room temperature, primary antibody (1:50 dilution, in 1\% bovine serum albumin PBS) was applied at $4{ }^{\circ} \mathrm{C}$ overnight in a humidified chamber. Primary p62 antibody (Santa Cruz Biotechnology, Inc.) was probed at $4{ }^{\circ} \mathrm{C}$ overnight. Each step was succeeded by 3 TBS rinses, and the bound antibody 


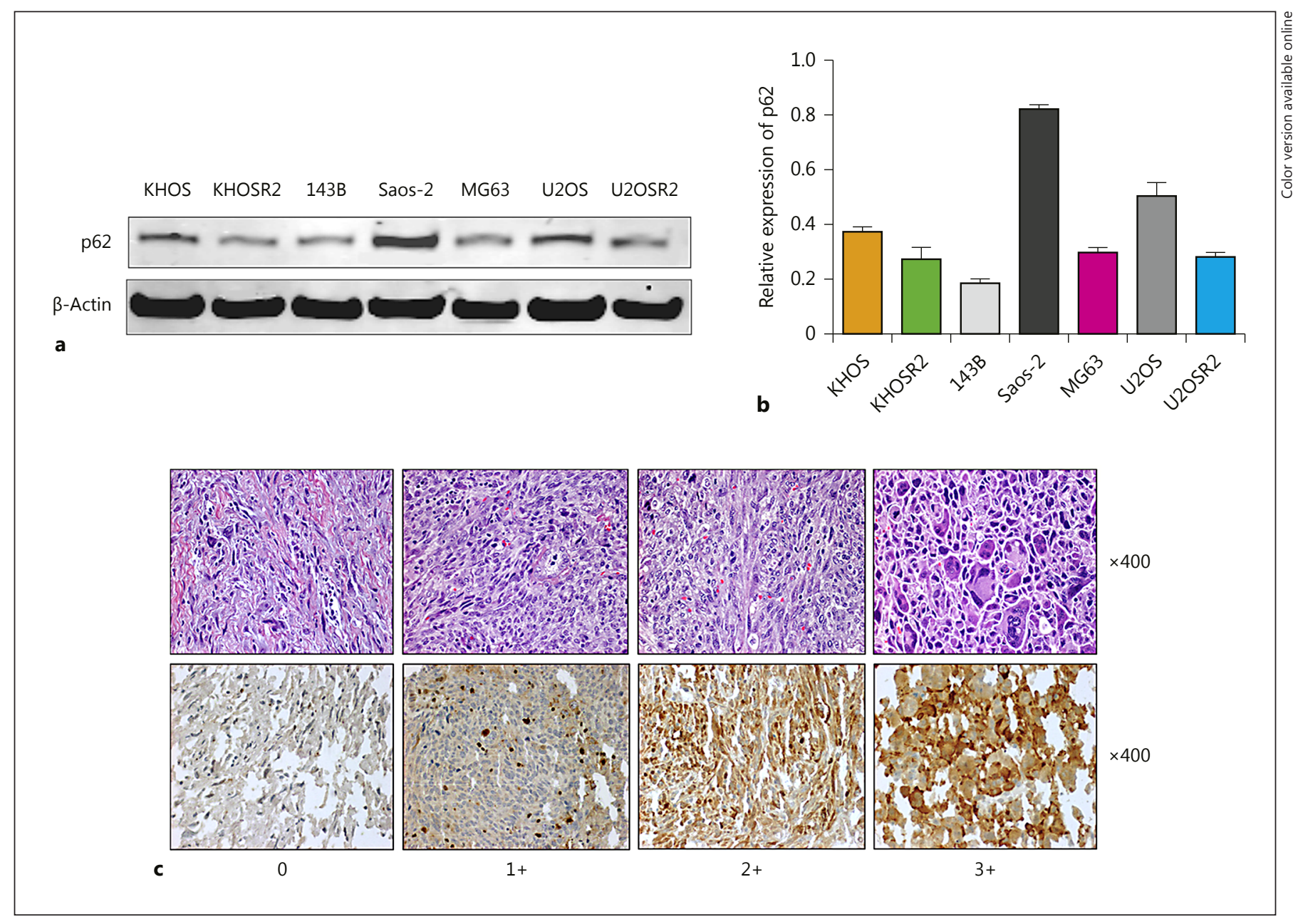

Fig. 1. Expression of protein p62 in osteosarcoma cell lines and osteosarcoma patient tissues. a Expression of p62 in osteosarcoma cell lines by western blotting. b Western blots of $\mathrm{p} 62$ from a were analyzed by densitometry, and quantitative results of p62 were presented as relative expression. c Representative images of different immunohistochemical staining intensities of p62 or HE stain- ing are shown in osteosarcoma tissues. The percentage of cells that showed positive cytoplasmic staining for p62 was calculated after analysis of the entire spot. Based on the p62 staining intensities in the tumor samples, the staining patterns were categorized into 4 groups: no staining $(0)$, weak staining $(1+)$, moderate staining $(2+)$, and strong staining $(3+)$. Original magnification, $\times 400$. on the array was detected using SignalStain ${ }^{\circledR}$ Boost Detection Reagent (Cell Signaling Technology) and SignalStain ${ }^{\circledR}$ DAB (Cell Signaling Technology). Finally, all the sections were counterstained with Hematoxylin QS (Vector Laboratories), and the slide was mounted with VectaMount AQ (Vector Laboratories) for long-term preservation.

\section{Evaluation of Immunohistochemical Staining}

Immunostained slides were evaluated under the microscope. The immunostaining intensity pattern of p62 was assessed on the following semi-quantitative scale: no staining $(0)$; weak staining $(1+)$; moderate staining $(2+)$; and strong staining (3+). The evaluation score of the p62 staining was completed by 2 independent investigators in the Sarcoma Biology Laboratory who were blinded to the clinicopathologic data, and a consensus was reached in all cases. The tumor necrosis was collected from the clinical data. It was based on the percentage of tumor tissues necrosis of pathological specimens (good response: $\geq 90 \%$ necrosis; poor response: $<90 \%$ necrosis). p62 staining images were obtained using a Nikon Eclipse Ti-U fluorescence microscope (Nikon Corp.) with a SPOT RT digital camera (Diagnostic Instruments, Inc.).

\section{Statistical Analysis}

GraphPad Prism5 software (GraphPad Software, Inc.) was used for statistical analyses. Statistical significance was assessed using independent two-tailed Student $t$ tests for independent data. Kaplan-Meier plots and log-rank tests were used to compare the differences in survival curves. The $\chi^{2}$ test was used to analyze the relationship between p62 expression and osteosarcoma clinical pathological parameters. Prognostic factors associated with overall 
Table 1. p62 staining characteristics of osteosarcoma specimens

\begin{tabular}{lllcc}
\hline p62 staining & No staining, $n(\%)$ & $1+$ staining, $n(\%)$ & $2+$ staining, $n(\%)$ & $3+$ staining, $n(\%)$ \\
\hline Primary & $3(3.8)$ & $11(13.9)$ & $10(12.7)$ & $14(17.7)$ \\
Recurrence & $11(13.9)$ & $2(2.5)$ & $1(1.3)$ \\
Metastasis & $1(1.3)$ & $18(22.8)$ & $5(6.3)$ & $3(3.8)$ \\
\hline Total & $4(5.1)$ & $40(50.6)$ & $17(21.5)$ & $18(22.8)$ \\
\hline
\end{tabular}

Table 2. Histological response to preoperative chemotherapy and p62 immunostaining

\begin{tabular}{llll}
\hline & $\begin{array}{l}\text { Good response }{ }^{\mathrm{a}} \% \text { pre- } \\
\text { operative chemotherapy) }\end{array}$ & $\begin{array}{l}\text { Poor response }{ }^{\mathrm{b}} \text { (\% pre- } \\
\text { operative chemotherapy) }\end{array}$ & $\begin{array}{l}\text { N/A (\% preoperative } \\
\text { chemotherapy) }\end{array}$ \\
\hline $\begin{array}{l}\text { p62 strong staining } \\
\text { p62 weak staining }\end{array}$ & $8(80.0 \%)$ & $18(41.9 \%)$ & $9(40.9 \%)$ \\
Total & $2(20.0 \%)$ & $25(58.1 \%)$ & $13(59.1 \%)$ \\
\hline
\end{tabular}

N/A, not applicable. ${ }^{a} \geq 90 \%$ necrosis. ${ }^{b}<90 \%$ necrosis.

survival or 5-year survival were investigated through the Cox proportional hazards regression model in a stepwise manner. Only those factors that were statistically significant $(p<0.05)$ in the univariate survival analysis were included in the multivariate analyses. All the results were presented as mean $\pm \mathrm{SD}$, and $p$ values $<0.05$ were regarded as statistically significant.

\section{Results}

\section{p62 Expression in Osteosarcoma Cell Lines and} Tissues

We first tested the expression of p62 in osteosarcoma cell lines. Western blot analysis revealed that p62 was expressed differently in every cell line (U2OS, KHOS, Saos2, MG63, U2OSR2, KHOSR2, and 143B). We observed a relatively low expression of p62 in the osteosarcoma cell lines 143B, KHOSR2, and U2OSR2, whereas U2OS, KHOS, and Saos-2 showed a relatively high expression (Fig. 1a, b). We also evaluated the expression of other autophagy-associated proteins, including LC3 and Atg5, in osteosarcoma cell lines by western blotting; we only found the decreased expression of p62, but not LC3 and Atg5, which was correlated with multidrug resistance in these cell lines (see online suppl. Fig. S1; for all online suppl. material, see www.karger.com/doi/10.1159/000487437). We further analyzed the expression of p62 in osteosar- coma tissues. The immunohistochemical staining showed p62 in the cytoplasm. Among the evaluable specimens, 75 of 79 (94.9\%) patient tissues exhibited p62 immunostaining, ranging from no staining ( 4 of $79,5.1 \%$ ) to $1+$ staining (40 of $79,50.6 \%), 2+$ staining $(17$ of $79,21.5 \%)$, and $3+$ staining $(18$ of $79,22.8 \%)$ (Table 1$)$. The stained specimens were subdivided into 2 categories: the low (1+) staining was classified as the p62 weak group (50.6\%), whereas the medium $(2+)$ and intense (3+) staining were classified as the p62 strong group (44.3\%) (Fig. 1c).

\section{Correlation between $p 62$ and Clinical Characteristics in Osteosarcoma Patients}

After p62 expression in TMA was analyzed, we compared patient prognosis with the expression level of p62. The differences in p62 expression between primary tumor tissues (patients without metastasis/recurrence) and tissues from patients with metastasis/recurrent disease were significant $(p<0.05)$ (Fig. 2a). The expression of $\mathrm{p} 62$ in patients with metastatic disease was significantly lower ( $p=0.0164)$ (Fig. 2b). In addition, patients with poor response to preoperative chemotherapy displayed weak expression of p62 compared to those who had a good response $(p=0.0110)$ (Fig. 2c; Table 2). Kaplan-Meier analysis demonstrated that patients with poor response to preoperative chemotherapy had a lower overall survival 


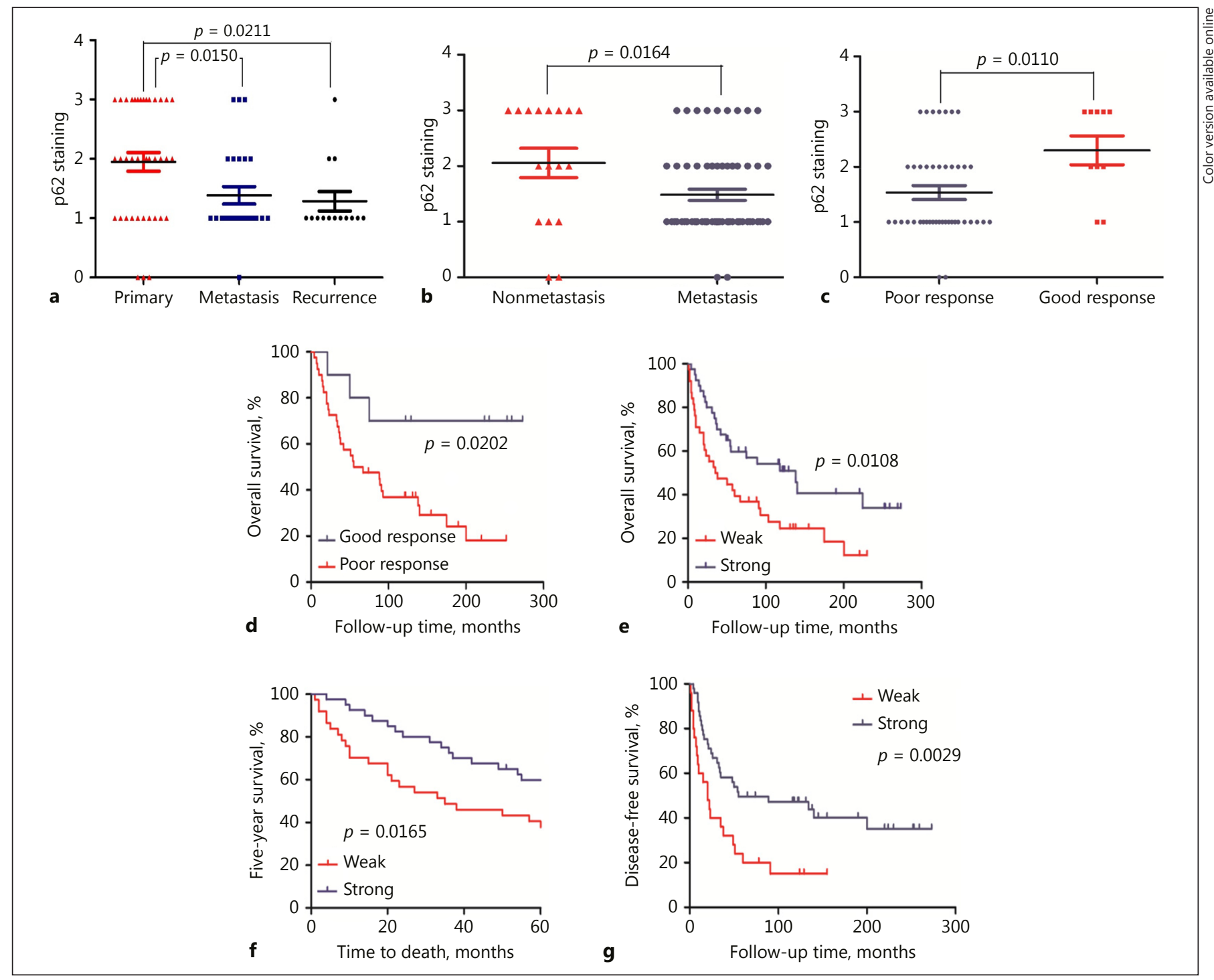

Fig. 2. Expression of p62 in osteosarcoma tissues of immunohistochemical staining and its clinical significance. a Distribution of p62 immunohistochemical staining scores in primary, metastatic, and recurrent osteosarcoma tissues. b Comparison of p62 immunostaining density between osteosarcoma tissues of patients with metastasis and nonmetastasis. c Comparison of 262 immunostaining density between good-response and poor-response osteosarcoma tissues based on the histological necrosis percentage after preoperative chemotherapy. d Kaplan-Meier overall survival curve: patients with osteosarcoma were subgrouped as either good or poor response to preoperative chemotherapy. e Kaplan-Meier overall survival curve: patients with osteosarcoma were subgrouped as either p62 weak staining (staining $\leq 1$ ) or strong staining (staining $\geq 2$ ). f Kaplan-Meier 5 -year survival curve: patients with osteosarcoma were subgrouped as either p62 weak staining (staining $\leq 1$ ) or strong staining (staining $\geq 2$ ). g Kaplan-Meier disease-free survival curve: patients with osteosarcoma were subgrouped as either p62 weak staining (staining $\leq 1$ ) or strong staining (staining $\geq 2$ ). rate $(p=0.0202)$ (Fig. 2d). However, there was no significant relationship between p62 expression and the other clinical pathological features of the patients, such as age $(p=0.3850)$, gender $(p=0.1461)$, and tumor site $(p=$ 0.2754) (Table 3). Compared to the osteosarcoma pa- tients of the p62 strong expression group, the KaplanMeier analysis showed that the weak p62 expression group had a lower overall survival rate $(p=0.0108)$ (Fig. 2e). Meanwhile, Kaplan-Meier analysis also showed that the weak p62 expression patients had a worse 5-year 
survival rate than the patients with strong p62 expression ( $p=0.0165$ ) (Fig. 2f). The 5-year survival rate for patients with weak p62 expression was $37.5 \%$, which was significantly lower than the rate of $65.7 \%$ in patients with strong p62 expression. The 5-year overall survival rate for patients with metastasis was $33.8 \%$, which was lower than the rate of $94.1 \%$ for patients with absent metastasis. Meanwhile, compared to a rate of $71.1 \%$ for patients with absent recurrence, the 5-year overall survival rate for patients with present recurrence was $47.7 \%$ (Table 4). Likewise, Kaplan-Meier analysis showed that patients with weak p62 expression had a lower disease-free survival rate than the patients with strong p62 expression $(p=0.0029)$ (Fig. $2 \mathrm{~g}$ ). The above data suggest that there is a close relationship between $\mathrm{p} 62$ expression and clinical prognosis as well as the pathological features of osteosarcoma, especially for tumor metastasis or recurrence.

To determine whether p62 expression was an independent prognostic factor for osteosarcoma patients, we used the Cox regression analysis. In the univariate Cox regression analysis, weak expression of $\mathrm{p} 62$, present metastasis or recurrence, and the response to preoperative chemotherapy were associated with shorter 5-year survival in osteosarcoma patients, whereas other clinicopathological features showed no prognosis correlations (Table 4). Im- portantly, multivariate Cox regression indicated that $\mathrm{p} 62$ expression was an independent predictor of 5-year survival $(p=0.0102)$ (Table 5). These results demonstrated that the p62 expression level independently predicts osteosarcoma outcomes.

\section{Discussion}

Autophagy has been shown to play complex roles in the regulation of cancer development and progression in different stages of tumorigenesis [16-19]. Specifically, after the tumor develops, autophagy is thought to support tumor growth $[17,20]$. In this study, we found p62 expressed in osteosarcoma cell lines, and p62 was decreased in recurrence or metastatic tumor tissues in comparison to the primary tumor tissues, which suggests that autophagy activity could be a mechanism associated with metastasis or recurrence in osteosarcoma patients.

Recently, accumulation of $\mathrm{p} 62$ has been used as a marker for autophagy inhibition [21-24]. Previous studies have demonstrated aberrant $\mathrm{p} 62$ expression to be associated with prognosis in various tumors $[12,13,25,26]$. In our study, we found differential expression of p62 in osteosarcoma cell lines. Interestingly, we observed a rela-

Table 3. The relationship between p62 expression and clinicopathological features of osteosarcoma

\begin{tabular}{|c|c|c|c|c|c|}
\hline $\begin{array}{l}\text { Clinicopathological } \\
\text { features }\end{array}$ & $\begin{array}{l}\text { Cases, } \\
n(\%)\end{array}$ & $\begin{array}{l}\text { p62 expression } \\
\text { N/A, } n(\%)\end{array}$ & $\begin{array}{l}\text { p62 expression } \\
\text { weak, } n(\%)\end{array}$ & $\begin{array}{l}\text { p62 expression } \\
\text { strong, } n(\%)\end{array}$ & $p$ value \\
\hline $\begin{array}{l}\text { All patients } \\
\text { Aoe }\end{array}$ & $79(100)$ & $4(5.1)$ & $40(50.6)$ & Age & \\
\hline$\leq 18$ years & $23(29.1)$ & $1(4.3)$ & $10(43.5)$ & $12(52.2)$ & \multirow[t]{2}{*}{0.3850} \\
\hline$>18$ years & $56(70.9)$ & $3(5.4)$ & $30(53.6)$ & $23(41.1)$ & \\
\hline \multicolumn{6}{|l|}{ Gender } \\
\hline Male & $49(62.0)$ & $2(4.1)$ & $22(44.9)$ & $25(51.0)$ & \multirow[t]{2}{*}{0.1461} \\
\hline Female & $30(38.0)$ & $2(6.7)$ & $18(60.0)$ & $10(33.3)$ & \\
\hline \multicolumn{6}{|l|}{ Tumor site } \\
\hline Femur & $32(40.5)$ & $1(3.1)$ & $18(56.3)$ & $13(40.6)$ & \multirow[t]{4}{*}{0.2754} \\
\hline Tibia & $15(19.0)$ & $1(6.7)$ & $6(40.0)$ & $8(53.3)$ & \\
\hline Humeral bone & $7(8.9)$ & & $2(28.6)$ & $5(71.4)$ & \\
\hline Other & $25(31.6)$ & $2(8.0)$ & $14(56.0)$ & $9(36.0)$ & \\
\hline \multicolumn{6}{|l|}{ Metastasis } \\
\hline Absent & $17(21.5)$ & $2(11.8)$ & 3 (17.6) & $12(70.6)$ & \multirow[t]{2}{*}{0.0164} \\
\hline Present & $62(78.5)$ & $2(3.2)$ & $37(59.7)$ & $23(37.1)$ & \\
\hline \multicolumn{6}{|l|}{ Recurrence } \\
\hline Absent & $52(65.8)$ & $3(5.8)$ & $21(40.4)$ & $28(53.8)$ & \multirow[t]{2}{*}{0.0121} \\
\hline Present & $27(34.2)$ & $1(3.7)$ & $19(70.4)$ & $7(25.9)$ & \\
\hline
\end{tabular}

N/A, not applicable. 
tively low expression of p62 in the osteosarcoma cell line $143 \mathrm{~B}$, which was discovered to be highly metastatic in the lungs of mice after subcutaneous and intramuscular xenotransplantations $[27,28]$. Expression of p62 was lower in the multidrug-resistant osteosarcoma cell lines U2OSR2 and KHOSR2. To define the relationship between p62 expression and clinical behavior in osteosarcoma, we analyzed the immunohistochemical staining of p62 in osteosarcoma tissue samples of patients and discovered a close relationship between p62 expression and clinical characteristics and outcomes. Differences in p62 expression from $1+$ to $3+$ staining were detected in $94.9 \%$ of the tumor samples examined, which indicates that p62 expression is frequent in osteosarcoma.

However, expression of p62 is not associated with patients' age, gender, and tumor site of osteosarcoma. In established tumors, autophagy responses usually assist tumor cells with intracellular and environmental stress, thus favoring tumor metastasis [29]. As compared to the primary group, our results showed that the recurrent and metastatic groups of osteosarcoma patients had weaker p62 expression. Consistent with our result, colorectal cancer also showed decreased p62 expression in the recurrent and metastatic groups as compared to the nonrecurrent and nonmetastatic groups [30]. Therefore, under an active autophagy status, decreased p62 expression may have a relationship with tumor metastasis and recurrence. Many studies have implicated that autophagy activities are enhanced in response to treatment, such as chemotherapy, which contributes to treatment resistance in cancer cells [31-33].

Increased autophagy activities have been reported to increase cell growth and promote chemoresistance in osteosarcoma cells [34-36]. In this study, we found decreased p62 expression in osteosarcoma patients with poor response to preoperative chemotherapy. These results suggest that p62 is most likely to be a marker associated with autophagy flux and a prognostic factor in osteo- sarcoma. This hypothesis is also supported by recent reports showing that $\operatorname{Ref}(2) \mathrm{P}$ - the Drosophila ortholog of p62 - was used to monitor autophagy flux, and p62 was also deemed as the best reporter protein to monitor autophagy, and it was degraded at a basal rate by autophagy activity $[37,38]$.

Additionally, our study showed that osteosarcoma patients with weak p62 stains had a worse survival rate and disease-free survival rate than patients with tumors that

Table 4. Univariate analysis of prognostic factors in all osteosarcoma patients

\begin{tabular}{|c|c|c|}
\hline Variable & $\begin{array}{l}\text { Five-year } \\
\text { survival, \% }\end{array}$ & $p$ value \\
\hline \multicolumn{3}{|l|}{ Age } \\
\hline$\leq 18$ years & 52.1 & 0.4150 \\
\hline$>18$ years & 46.4 & \\
\hline \multicolumn{3}{|l|}{ Gender } \\
\hline Male & 42.8 & 0.3310 \\
\hline Female & 56.0 & \\
\hline \multicolumn{3}{|l|}{ Tumor site } \\
\hline Femur & 59.3 & 0.4714 \\
\hline Tibia & 33.3 & \\
\hline Humeral bone & 57.1 & \\
\hline Other & 44.0 & \\
\hline \multicolumn{3}{|l|}{ Metastasis } \\
\hline Absent & 94.1 & $<0.0001$ \\
\hline Present & 33.8 & \\
\hline \multicolumn{3}{|l|}{ Recurrence } \\
\hline Absent & 71.1 & 0.0206 \\
\hline Present & 47.7 & \\
\hline \multicolumn{3}{|l|}{ p62 expression } \\
\hline Weak & 37.5 & 0.0165 \\
\hline Strong & 65.7 & \\
\hline \multicolumn{3}{|c|}{ Response to preoperative chemotherapy } \\
\hline Good & 80.0 & 0.0182 \\
\hline Poor & 52.6 & \\
\hline
\end{tabular}

Table 5. Multivariate survival analysis (5-year survival)

\begin{tabular}{llrr}
\hline Variable & Hazard ratio & 95\% CI & $p$ value \\
\hline p62 expression & 2.170 & $1.152-4.085$ & 0.0102 \\
Metastasis & 4.370 & $2.224-8.585$ & $<0.0001$ \\
Recurrence & 3.410 & $2.146-7.026$ & 0.1080 \\
Response to preoperative chemotherapy & 4.022 & $1.744-6.369$ & 0.0136 \\
\hline
\end{tabular}

CI, confidence interval.

Expression and Clinical Implication of p62 in Osteosarcoma 
had strong p62 stains. Therefore, decreased p62 expression might be a potential biomarker indicative of a mechanism that causes failed treatment in osteosarcoma. Currently, several studies investigating autophagy inhibitors correlated with preclinical and clinical trials are ongoing in different cancers [39-41]. In osteosarcoma, the autophagy inhibitor chloroquine has been noticed to decrease cell proliferation and growth [42]. Moreover, upregulation of p62 is an effective approach for inhibiting autophagy activity in tumors. In cisplatin-resistant osteosarcoma cells, chloroquine could block autophagy and increase chemosensitivity [43]. Autophagy inhibitor 3-MA combined with doxorubicin or cisplatin could improve the therapeutic response to chemotherapy drugs in U2OS, Sao-2, and MG63 osteosarcoma cell lines [10, 44]. Therefore, enhancing the level of p62 may be an effective therapy for cancer treatment. p62 vaccination has been used to suppress tumor metastasis in mice with sarcoma and in dogs with mammary tumors. It also dramatically decreased the number and sizes of lung or lymphatic metastases [45-47]. For improving the treatment of osteosarcoma, p62 vaccine may also be used as a novel cancer therapy for osteosarcoma in the future.

\section{Conclusion}

Our study demonstrated that p62 has an important role in osteosarcoma. The level of p62 expression was directly associated with clinical outcome, especially since, as an autophagy-associated protein, p62 is closely related to tumor recurrence, metastasis, and prognosis in osteosarcoma. Our data suggest that p62 may be a potential novel molecular biomarker in osteosarcoma.

\section{Acknowledgments}

This project was partially supported by grants from the Gattegno and Wechsler funds. Dr. Duan is supported, in part, through a grant from the Sarcoma Foundation of America (SFA), a grant from the National Cancer Institute (NCI)/National Institutes of Health (NIH), UO1, CA151452-01, a pilot grant from Sarcoma SPORE/NIH, and a grant from an Academic Enrichment Fund of MGH Orthopedic Surgery.

\section{Disclosure Statement}

The authors report no conflicts of interest in relation to this work.

\section{References}

1 Bielack SS, Hecker-Nolting S, Blattmann C, Kager L: Advances in the management of osteosarcoma. F1000Res 2016;5:2767.

-2 Luetke A, Meyers PA, Lewis I, Juergens H: Osteosarcoma treatment - where do we stand? A state of the art review. Cancer Treat Rev 2014; 40:523-532.

3 Ferrari S, Mercuri M, Bacci G: Comment on "Prognostic factors in high-grade osteosarcoma of the extremities or trunk: an analysis of 1,702 patients treated on neoadjuvant Cooperative Osteosarcoma Study Group protocols." J Clin Oncol 2002;20:2910; author reply 2910-2911.

4 Osborne TS, Khanna C: A review of the association between osteosarcoma metastasis and protein translation. J Comp Pathol 2012;146: 132-142.

5 Meyers PA: Muramyl tripeptide (mifamurtide) for the treatment of osteosarcoma. Expert Rev Anticancer Ther 2009;9:1035-1049.

- 6 He JP, Hao Y, Wang XL, Yang XJ, Shao JF, Guo FJ, Feng JX: Review of the molecular pathogenesis of osteosarcoma. Asian Pac J Cancer Prev 2014;15:5967-5976.

7 Moore DD, Luu HH: Osteosarcoma. Cancer Treat Res 2014;162:65-92.
-8 Mathew R, Karp CM, Beaudoin B, Vuong N, Chen G, Chen HY, Bray K, Reddy A, Bhanot G, Gelinas C, Dipaola RS, Karantza-Wadsworth V, White E: Autophagy suppresses tumorigenesis through elimination of p62. Cell 2009; 137:1062-1075.

$>9$ Min L, Choy E, Pollock RE, Tu C, Hornicek F, Duan Z: Autophagy as a potential target for sarcoma treatment. Biochim Biophys Acta 2017;1868:40-50.

10 Zhao D, Yuan H, Yi F, Meng C, Zhu Q: Autophagy prevents doxorubicin-induced apoptosis in osteosarcoma. Mol Med Rep 2014;9: 1975-1981.

-11 Sui X, Chen R, Wang Z, Huang Z, Kong N, Zhang M, Han W, Lou F, Yang J, Zhang Q, Wang X, He C, Pan H: Autophagy and chemotherapy resistance: a promising therapeutic target for cancer treatment. Cell Death Dis 2013;4:e838.

12 Moscat J, Diaz-Meco MT: p62 at the crossroads of autophagy, apoptosis, and cancer. Cell 2009; 137:1001-1004.

13 Wei H, Wang C, Croce CM, Guan JL: p62/ SQSTM1 synergizes with autophagy for tumor growth in vivo. Genes Dev 2014;28: 1204-1216.

14 Lippai M, Low P: The role of the selective adaptor p62 and ubiquitin-like proteins in autophagy. Biomed Res Int 2014;2014:832704.
15 Jimenez-Sanchez M, Menzies FM, Chang YY, Simecek N, Neufeld TP, Rubinsztein DC: The Hedgehog signalling pathway regulates autophagy. Nat Commun 2012;3:1200.

16 Kenific CM, Thorburn A, Debnath J: Autophagy and metastasis: another double-edged sword. Curr Opin Cell Biol 2010;22:241-245.

17 White E, DiPaola RS: The double-edged sword of autophagy modulation in cancer. Clin Cancer Res 2009;15:5308-5316.

18 Galindo-Moreno M, Giraldez S, Saez C, Japon MA, Tortolero M, Romero F: Both p62/ SQSTM1-HDAC6-dependent autophagy and the aggresome pathway mediate CDK1 degradation in human breast cancer. Sci Rep 2017; 7:10078.

19 Choi J, Kim H, Bae YK, Cheong H: REP1 modulates autophagy and macropinocytosis to enhance cancer cell survival. Int J Mol Sci 2017;18.

20 Yang ZJ, Chee CE, Huang S, Sinicrope FA: The role of autophagy in cancer: therapeutic implications. Mol Cancer Ther 2011;10: 1533-1541.

21 Gal J, Strom AL, Kilty R, Zhang F, Zhu H: p62 accumulates and enhances aggregate formation in model systems of familial amyotrophic lateral sclerosis. J Biol Chem 2007;282:1106811077. 
-22 Hara T, Takamura A, Kishi C, Iemura S, Natsume T, Guan JL, Mizushima N: FIP200, a ULK-interacting protein, is required for autophagosome formation in mammalian cells. J Cell Biol 2008;181:497-510.

23 Komatsu M, Waguri S, Koike M, Sou YS, Ueno T, Hara T, Mizushima N, Iwata J, Ezaki J, Murata S, Hamazaki J, Nishito Y, Iemura S, Natsume T, Yanagawa T, Uwayama J, Warabi E, Yoshida H, Ishii T, Kobayashi A, Yamamoto $\mathrm{M}$, Yue Z, Uchiyama Y, Kominami E, Tanaka K: Homeostatic levels of p62 control cytoplasmic inclusion body formation in autophagy-deficient mice. Cell 2007;131:11491163.

-24 Bjorkoy G, Lamark T, Pankiv S, Overvatn A, Brech A, Johansen T: Monitoring autophagic degradation of p62/SQSTM1. Methods Enzymol 2009;452:181-197.

25 Wang X, Du Z, Li L, Shi M, Yu Y: Beclin 1 and p62 expression in non-small cell lung cancer: relation with malignant behaviors and clinical outcome. Int J Clin Exp Pathol 2015;8:1064410652.

26 Zhang J, Yang Z, Dong J: p62: an emerging oncotarget for osteolytic metastasis. J Bone Oncol 2016;5:30-37.

-27 Tome Y, Kimura H, Maehara H, Sugimoto N, Bouvet M, Tsuchiya H, Kanaya F, Hoffman RM: High lung-metastatic variant of human osteosarcoma cells, selected by passage of lung metastasis in nude mice, is associated with increased expression of $\alpha(v) \beta(3)$ integrin. Anticancer Res 2013;33:3623-3627.

-28 Brennecke P, Arlt MJ, Muff R, Campanile C, Gvozdenovic A, Husmann K, Holzwarth N, Cameroni E, Ehrensperger F, Thelen M, Born W, Fuchs B: Expression of the chemokine receptor CXCR7 in CXCR4-expressing human 143B osteosarcoma cells enhances lung metastasis of intratibial xenografts in SCID mice. PLoS One 2013;8:e74045.

29 Zhang J, Yang Z, Xie L, Xu L, Xu D, Liu X: Statins, autophagy and cancer metastasis. Int J Biochem Cell Biol 2013;45:745-752.
Kim YS, Shin JH, Bae MK, Lee CY, Kim DJ, Chung KY, Lee JG: Autophagy activity in pulmonary metastatic tumor tissues from colorectal cancer: a pilot study. Yonsei Med J 2014;55:1484-1488.

31 Fu Y, Wu P, Pan Y, Sun X, Yang H, Difiglia $\mathrm{M}, \mathrm{Lu} \mathrm{B}$ : A toxic mutant huntingtin species is resistant to selective autophagy. Nat Chem Biol 2017;13:1152-1154.

32 Liu L, Liao JZ, He XX, Li PY: The role of autophagy in hepatocellular carcinoma: friend or foe. Oncotarget 2017;8:57707-57722.

33 Helgason GV, Holyoake TL, Ryan KM: Role of autophagy in cancer prevention, development and therapy. Essays Biochem 2013;55: 133-151.

34 Xie Z, Xie Y, Xu Y, Zhou H, Xu W, Dong Q: Bafilomycin A1 inhibits autophagy and induces apoptosis in MG63 osteosarcoma cells. Mol Med Rep 2014;10:1103-1107.

35 Zou J, Zhang Y, Sun J, Wang X, Tu H, Geng S, Liu R, Chen Y, Bi Z: Deoxyelephantopin induces reactive oxygen species-mediated apoptosis and autophagy in human osteosarcoma cells. Cell Physiol Biochem 2017;42: 1812-1821.

36 O’Farrill JS, Gordon N: Autophagy in osteosarcoma. Adv Exp Med Biol 2014;804:147160.

37 Larsen KB, Lamark T, Overvatn A, Harneshaug I, Johansen T, Bjorkoy G: A reporter cell system to monitor autophagy based on p62/SQSTM1. Autophagy 2010;6:784-793.

38 DeVorkin L, Gorski SM: Monitoring autophagic flux using $\operatorname{Ref}(2) \mathrm{P}$, the Drosophila p62 ortholog. Cold Spring Harb Protoc 2014; 2014:959-966.

39 Arun B, Akar U, Gutierrez-Barrera AM, Hortobagyi GN, Ozpolat B: The PARP inhibitor AZD2281 (Olaparib) induces autophagy/mitophagy in BRCA1 and BRCA2 mutant breast cancer cells. Int J Oncol 2015;47:262-268.

40 Zhao X, Fang Y, Yang Y, Qin Y, Wu P, Wang T, Lai H, Meng L, Wang D, Zheng Z, Lu X, Zhang H, Gao Q, Zhou J, Ma D: Elaiophylin, a novel autophagy inhibitor, exerts antitumor activity as a single agent in ovarian cancer cells. Autophagy 2015;11:1849-1863.
41 Sobhakumari A, Schickling BM, LoveHoman L, Raeburn A, Fletcher EV, Case AJ, Domann FE, Miller FJ Jr, Simons AL: NOX4 mediates cytoprotective autophagy induced by the EGFR inhibitor erlotinib in head and neck cancer cells. Toxicol Appl Pharmacol 2013;272:736-745

42 Zhu YR, Zhou XZ, Zhu LQ, Yao C, Fang JF, Zhou F, Deng XW, Zhang YQ: The anti-cancer activity of the mTORC1/2 dual inhibitor XL388 in preclinical osteosarcoma models. Oncotarget 2016;7:49527-49538.

43 Shen C, Wang W, Tao L, Liu B, Yang Z, Tao $\mathrm{H}$ : Chloroquine blocks the autophagic process in cisplatin-resistant osteosarcoma cells by regulating the expression of p62/SQSTM1. Int J Mol Med 2013;32:448-456.

44 Chen R, Li X, He B, Hu W: MicroRNA-410 regulates autophagy-related gene ATG16L1 expression and enhances chemosensitivity via autophagy inhibition in osteosarcoma. Mol Med Rep 2017;15:1326-1334.

45 Venanzi F, Shifrin V, Sherman M, Gabai V, Kiselev O, Komissarov A, Grudinin M, Shartukova M, Romanovskaya-Romanko EA, Kudryavets Y, Bezdenezhnykh N, Lykhova O, Semesyuk N, Concetti A, Tsyb A, Filimonova M, Makarchuk V, Yakubovsky R, Chursov A, Shcherbinina V, Shneider A: Broad-spectrum anti-tumor and anti-metastatic DNA vaccine based on p62-encoding vector. Oncotarget 2013;4:1829-1835.

46 Gabai V, Venanzi FM, Bagashova E, Rud O, Mariotti F, Vullo C, Catone G, Sherman MY, Concetti A, Chursov A, Latanova A, Shcherbinina V, Shifrin V, Shneider A: Pilot study of p62 DNA vaccine in dogs with mammary tumors. Oncotarget 2014;5:1280312810.

47 Gabai VL, Shifrin VI: Feasibility analysis of p62 (SQSTM1)-encoding DNA vaccine as a novel cancer immunotherapy. Int Rev Immunol 2014;33:375-382. 